\title{
Effect of Gamma-Ray and Temperature on the Viscosity of Polystyrene
}

\author{
M. S. Buni W. A. Solyman S. A. Ali \\ Department of Physics / College of Education, \\ University of Mosul
}

Received

27 / 03 / 2011
Accepted

15 / 09 / 2011

\begin{abstract}
الخلاصة
تم في هذا البحث دراسة تأثير أثنعة كاما على اللزوجة المختزلة والذانية وثابت هويكنز

لمحلـول البوليستيرين في مـذيب البنزين. اذ تـم حساب متوسـط الـوزن الجزيئي للبوليستنيرين باستخدام معادلة مارك - هوينك - سوكارادا بالاعتماد على قيم اللزوجة الذاتئة. كما تم أيضاً دراسة تأثير درجة الحرارة ضمن المدى الحراري C٪ (60-25) على اللزوجة المختزلة. وقد بينت

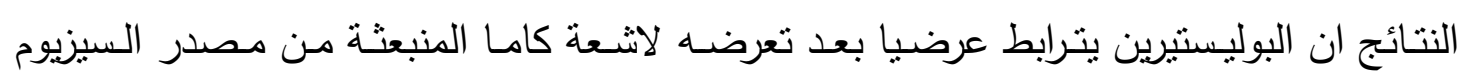
Cs في الهواء ويتحلل بزيادة درجة الحرارة.
\end{abstract}

\begin{abstract}
In this research the effect of gamma rays had been studied on the reduced viscosity and intrinsic viscosity and Huggins constant of polystyrene (PS) solution in the solvent benzene, by the determination of the average molecular weight of (PS) using Mark - Houwink - Sakurada equation depending on the values of intrinsic viscosity. The effect of temperature in the range $(25-60)^{\circ} \mathrm{C}$ on the reduced viscosity had been studied too. The results showed that (PS) undergoes crosslinking after irradiation in air with gamma rays emitted from $C s^{137}$ source and degradation with increasing temperature.
\end{abstract}

\section{Introduction}

Growing interest in irradiation of polymers and organic materials has been reported recently in the literature ${ }^{(1-9)}$. Radiation-induced corsslinking of polymers is the most well-known process in the field of industrial use of radiation. Polymers may either crosslink or degrade depending on their chemical nature and radiation used. Both processes take place simultaneously in most polymers under usual conditions. Also 
the molecular weight of polymers increases with increasing dose of radiation for crosslinking type of polymers.

Cross-linked polymeric materials have important advantages over their non-cross-linked analogous such as superior mechanical and chemical properties, higher thermal stability and lower temperature dependence of viscosity ${ }^{(10,11)}$.

PS is one of the most important material in the modern plastic industry which, has been used all over the world, due to its excellent physical properties and low-cost ${ }^{(12)}$.

Many studies on PS $\left(\mathrm{C}_{8} \mathrm{H}_{8}\right)$ after irradiation had been made ${ }^{(13-18)}$. The effect of $\gamma$-radiation on PS shows that it undergoes crosslinking ${ }^{(19)}$ as shown in fig. (1)

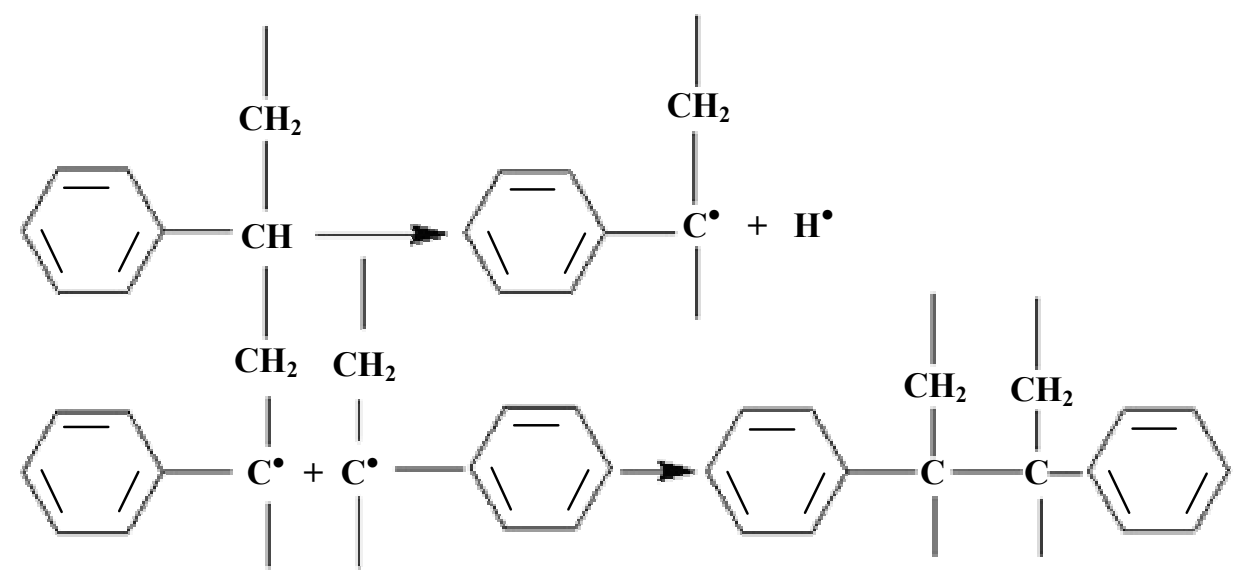

Fig. (1): Crosslinking of Polystyrene

The present work was undertaken to find out: 1) the average molecular weight of (PS) samples irradiated in air at low gamma radiation dose. 2) A new method for studing the effect of measuring temperature for a solvent and (PS) solution to determine the reduced viscosity.

\section{Theoretical part.}

The relative viscosity $\left(\eta_{r e l}\right)$ for dilute polymer solution was obtained by the expression ${ }^{(20)}$ :

$\eta_{\text {rel }}=\frac{\eta}{\eta_{0}}=\frac{t}{t_{0}}$

Where $\eta$ : solution viscosity, $\eta_{0}:$ solvent viscosity,

$t$ : efflux time of solution, $t_{0}$ : efflux time of solvent

The specific viscosity,

$\eta_{S P}=\frac{\eta-\eta_{0}}{\eta_{0}}=\frac{t-t_{0}}{t_{0}}=\frac{t}{t_{0}}-1=\eta_{\text {rel }}-1$

The reduced viscosity $\left(\eta_{\text {red }}\right)$, at each concentration $(C)$ was calculated from the relation ${ }^{(21)}$ 
$\eta_{\text {red }}=\frac{\eta_{s p}}{C}=\frac{t-t_{0}}{t_{0} c}=\frac{\eta_{r e l}-1}{C}$

The intrinsic viscosity $[\eta]$ is defined by the following relation:

$[\eta]=\lim _{c \rightarrow 0}\left(\frac{\eta}{C}\right)$

The molecular weight $\mathrm{M}$ of the samples was determined by the intrinsic viscosity $[\eta]$, whose relation is given by Mark - Houwink - Sakurada ${ }^{(22,}$ 23)

$[\eta]=K M^{a}$

Where $\mathrm{K}$ and a are constants, their values are $9.52 \times 10^{-5} \mathrm{dl} / \mathrm{g}$ and 0.744 , respectively, for PS (solvent: Benzene) at $25^{\circ} \mathrm{C}$.

\section{Experimental Part}

PS foils used in this research were prepared following the method described in reference ${ }^{(24)}$. The PS solution was prepared by solving $1 \mathrm{gm}$ of PS foil in $100 \mathrm{~cm}^{3}$ of Analar Benzene at temperature $(25 \pm 0.1)^{\circ} \mathrm{C}$ to get a solution of $\mathrm{g} / \mathrm{dl}$ concentration then this was diluted to get different concentrations between $(0.1-1) \mathrm{g} / \mathrm{dl}$. This method was used to prepare samples for both irradiated and non radiated PS foils.

In the present work the viscometric measurements were carried out in an ordinary Cannon-Fenske capillary viscometer (shown in fig.2) thermostated at $25^{\circ} \mathrm{C}$ by a water bath ${ }^{(25)}$.

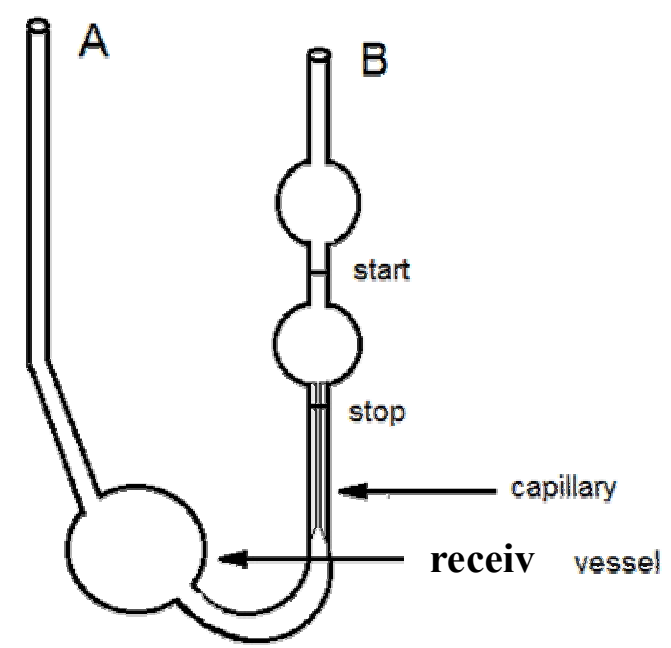

Fig. (2): Schematic of a Glass Capillary

(Cannon-Fenske) Viscometer

PS foils of dimension (1.0x1.0x0.05) $\mathrm{cm}$ were irradiated in air with $\gamma$-ray obtained from Cs137 source.

We studied the effect of $\gamma$-ray (emitted from Cs137 source of activity $1 \mu$ $\mathrm{Ci}$ and energy $0.662 \mathrm{Mev}$ ) on PS samples for two periods of irradiation time. 


\section{Results and Discussion}

\section{$4.1 \gamma$-ray effect}

The relation between the reduced viscosity and concentration of PS solutions (before and after irradiation) at $25^{\circ} \mathrm{C}$ is shown in fig. (3). It is clear from this fig. that the increase in concentration from $0.2 \mathrm{~g} / \mathrm{dl}$ will cause an increase in the reduced viscosity and this is due to the increase in friction between the polymer molecules with each other and with the solvent molecules (26). The values of $\frac{\eta_{s p}}{C}$ before irradiation is lower than that irradiated with $\gamma$-ray and this is because of that ions and free radicals formed may be join together to form a large polymer series which leads to crosslinking. While reduced viscosity increased ${ }^{(25)}$ with decreasing concentration less than $0.2 \mathrm{~g} / \mathrm{dl}$ and this is due to the change of polymer solution from non-Newtonian flow to Newtonian flow ${ }^{(27)}$.

The intrinsic viscosity $[\eta]$ of PS solutions was determined from the linear plots of reduced viscosity $\left(\eta_{r e d}\right)$ with concentration (C) which is achieved by extrapolation to zero concentration.

The effect of $\gamma$-radiation on intrinsic viscosity is shown in fig. (4), there is a linear increase in $[\eta]$ with the increase of irradiation time.

The average molecular weight $\mathrm{M}$ of PS samples was calculated from eq. (5). The increase in molecular weight $\Delta \mathrm{M}$ with irradiation time is shown in fig. (5). It is clear that there is an increase in molecular weight when the irradiation increases during the limit of irradiation and this due to the free radicals and ions fromed during irradiation of (PS) by gamma rays will join together to gives large series of (PS) which leads to an increase in reduced viscosity and then an increase in the average molecular weight of (PS).

Further analysis of fig (3) and from Huggins equation ${ }^{(28)}$

$\frac{\eta_{s p}}{C}=[\eta]+k_{H}[\eta]^{2} C$.

Where $K_{H}$ is the Huggin's viscometric constant, its value for a specific solvent has been assumed to contribute to its power, the lower the value of $\mathrm{K}_{\mathrm{H}}$, the better the solvent, or high value of $\mathrm{K}_{\mathrm{H}}$ is characteristic of poor solvent. The values of $\mathrm{K}_{\mathrm{H}}$ had been determined from the slope of $\frac{\eta_{S P}}{C}$ vs. C in fig. (3) and plotted as a function of irradiation time and $\mathrm{M}$, this is shown in fig. $(6,7)$. It is clear from these figures that $\mathrm{K}_{\mathrm{H}}$ decreases with irradiation time and $\mathrm{M}$ too, because the increase in gamma rays cause an increase in the intrinsic viscosity as shown in fig (4).

\subsection{Effect of Temperature}

The relation between temperature of the polymer solutions and their viscosity $(\eta)$ expressed ${ }^{(27,29)}$ as: 
$\eta=A \exp (-Q / R T)$

Where $\mathrm{A}$ is a pre-exponential term, $\mathrm{Q}$ is activation energy of viscous flow, $\mathrm{R}$ is the gas constant.

We studied the reduced viscosity $\left(\eta_{\text {red }}\right)$ for two concentrations $(0.4,1) \mathrm{g} / \mathrm{dl}$ in the temperature range $(25-60)^{\circ} \mathrm{C}$. The effect of temperature upon $\frac{\eta_{S P}}{C}$ for PS should depend strongly upon the nature of the solvent, in a very good solvent, therefore, a temperature increase should cause a decrease in $\frac{\eta_{s p}}{C}$, while in a poor solvent, a temperature increase should result in an increase of $\frac{\eta_{S P}}{C}$.

The results are shown in fig. (8) which agrees with eq. (7), it is clear that the viscosity decreases with increasing temperature, this can be explained physically that the increase in measuring temperature will lead to decrease in activation energy $\mathrm{Q}$ and then decrease in $(\eta)$ and chemically the increase in temperature will lead to a break and shortage of polymer series which in turn leads to a decrease in viscosity.

The logarithmic dependence of $\frac{\eta_{S P}}{C}$ upon the reciprocal of measuring temperature is represented by a straight line as shown in fig. (9) which shows a good agreement with eq. (7).

\section{Conclusion}

1. From this work it can be concluded that PS undergoes crosslinking by $\gamma$-irradiation in the limit of irradiation time used.

2. The increase in concentration of PS solution (0.2-1) g/dl causes an increase in reduced viscosity when samples irradiated with $\gamma$-ray and dissolved in analar benzene while the decrease of concentration below $0.2 \mathrm{~g} / \mathrm{dl}$ cause an increase in reduced viscosity.

3. Intrinsic viscosity and molecular weight of PS increases with $\gamma$ irradiation dose while Huggins coefficient decreases.

4. Reduced viscosity of PS dissolved in analar benzene decreases with increasing measured temperature in the range $(25-60)^{\circ} \mathrm{C}$. 


\section{References}

1) Loo, J.S., OOi.G.P., and Boey. F.Y, Science Direct, 26: 1359, (2005).

2) Leticia, M.O., Elmo, S.A., and Selma, M.L., Polymer Degradation and Stability, 91: 2157, (2006).

3) Chu.C.C., Zhang, L., Coyne, L.D., Journal of Applied Polymer Science, 56: 1275, (2009).

4) Virendra.S, PhD thesis, Panjab Uni. Chandigarh (2006).

5) Sevil, U.A., Quven.Q, Kovacs.A, Radiation Phys. And Chem., 67: 575, (2003).

6) Buni, M, Mheemeed, Hasan, H.I, J. Edu., 25: 86, (1996).

7) Buni, M.S., Saeed, K.I., J.Edu, 31: 48, (1998).

8) Manssor, M.I., Buni, M.S., J. Edu, 29: 82, (1998).

9) Buttrus, M.H., Ali, L.H., Buni, M.S. Mu'tah Journal for Research and studies, 9: 281, (1994).

10) Joel, M.P., Kamlesh, P.N., Tetrahedron, 60: 7205, (2004).

11) Rosen, S.L. Fundamental Principles of Polymeric Materials, $2^{\text {nd }}$ Ed. Wiley, New York (1993).

12) Rabie, S.T., Mahran, A.M., Kamel, E.M., Journal of Applied Science Research, 4: 2018, (2008).

13) Buni, M.S., Abdul-Aziz, Q, M, Aljouher, D.A., Arab Journal of Phys., 8: 83, (1987).

14) Calcagni, L., Foti, G., Nucl. Inst. And Meth. B19/20: 895, (1987).

15) Faraj, S.H., Salih, S.M., Radiation Effects, 55: 149, (1981).

16) Tabata, Y, Radial Phys. Chem., 14: 235, (1979).

17) Nichol, J.M. O'Donnel, J.H., Rahman, N.P., J. Polymer Sci, Polymer Phys. Ed. 15: 2919, (1977).

18) Flavio, F. S., Katia, A.S., Elmo, S.A., Science Direct, 93: 2199, (2008).

19) Henry, A., Radiat Phys. Chem., 15: 65, (1980).

20) Martins, R.M., Silva, C. A., Becker, C., polimeros, 12: 109, (2002).

21) Ibrahim, B.A., Ph. D thesis, Univ. of Manchester, (1980).

22) Brandrup, J., Immergut, E., Polymer Handbook, $2^{\text {nd }}$ Ed. John Wiley, New York (1975).

23) Joon, O., Taikyue, R., Bulletin of Korean Chem. Soc., 2: 129, (1981).

24) Buni, M.S. Msc. Thesis, Univ. of Baghdad, (1983).

25) Horta, A. Saiz, E., Barrales, J., Polymers, 27: 139, (1986).

26) Farhood, A. K., Albadry, M. B, Iraqi J, Sci, 26, 89, (1985).

27) Tager, A., Physical Chemistry of Polymers, Moscow, (1978).

28) Sara, A., Arvidson, B., Todd, R.F., Carbohydrate Polymers, 65: 144, (2006).

29) Maissa, P., Seurin, M.J. Sixou, P., Polymer Bulletin, 5: 257, (1986). 
M. S. Buni \& W. A. Solyman \& S. A. Ali

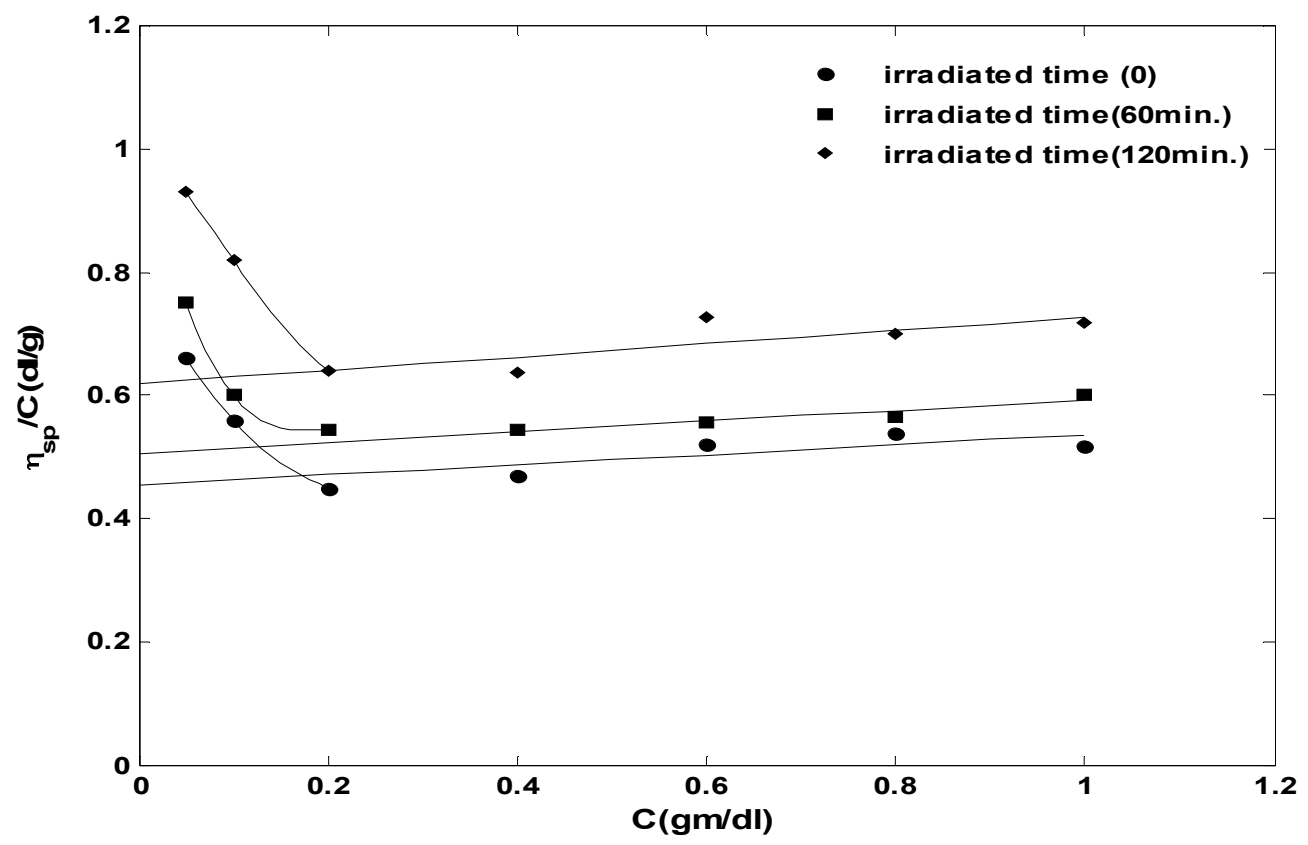

Fig (3) Plot of $\eta_{\text {sp }} / C$ vs $C$ of Ps samples in Benzene at 25

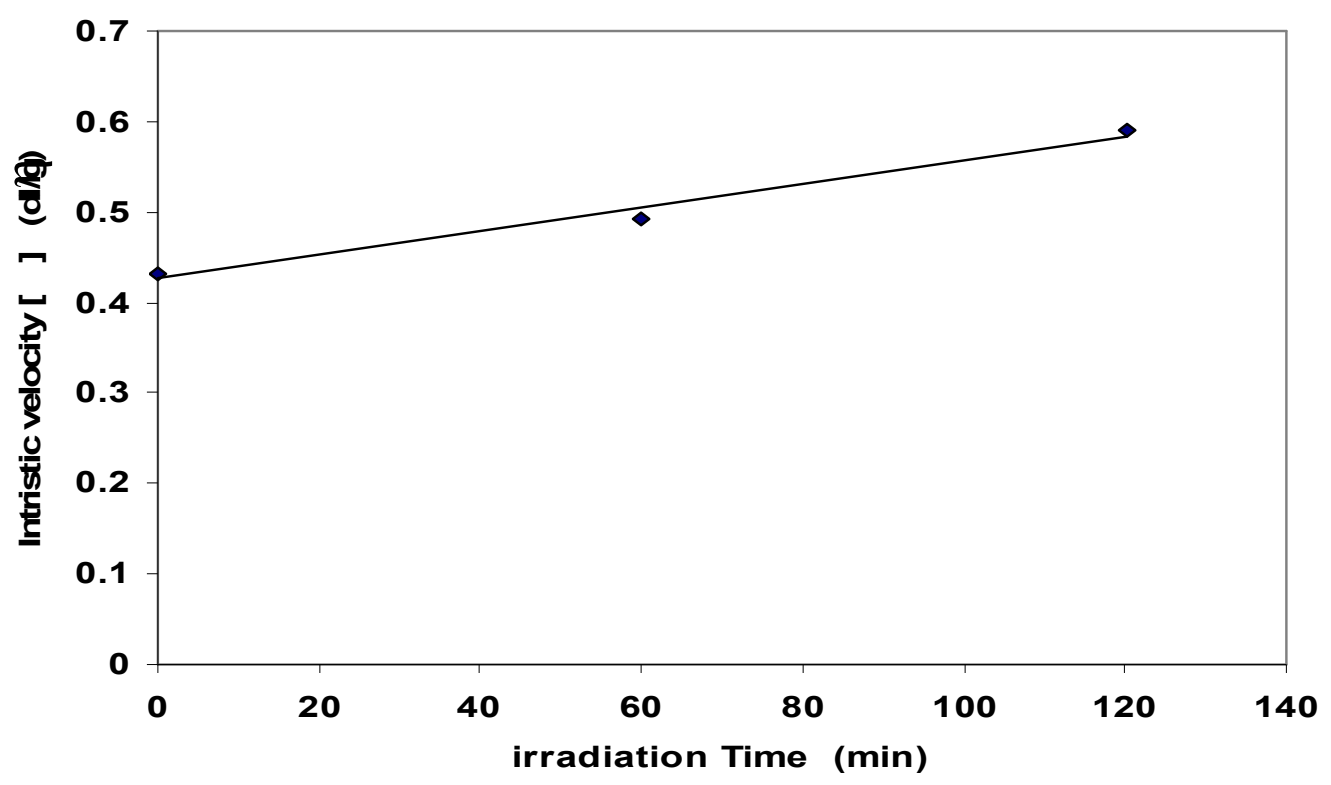

Fig (4) Effect of irradiation time on intrinsic viscosity of Ps 


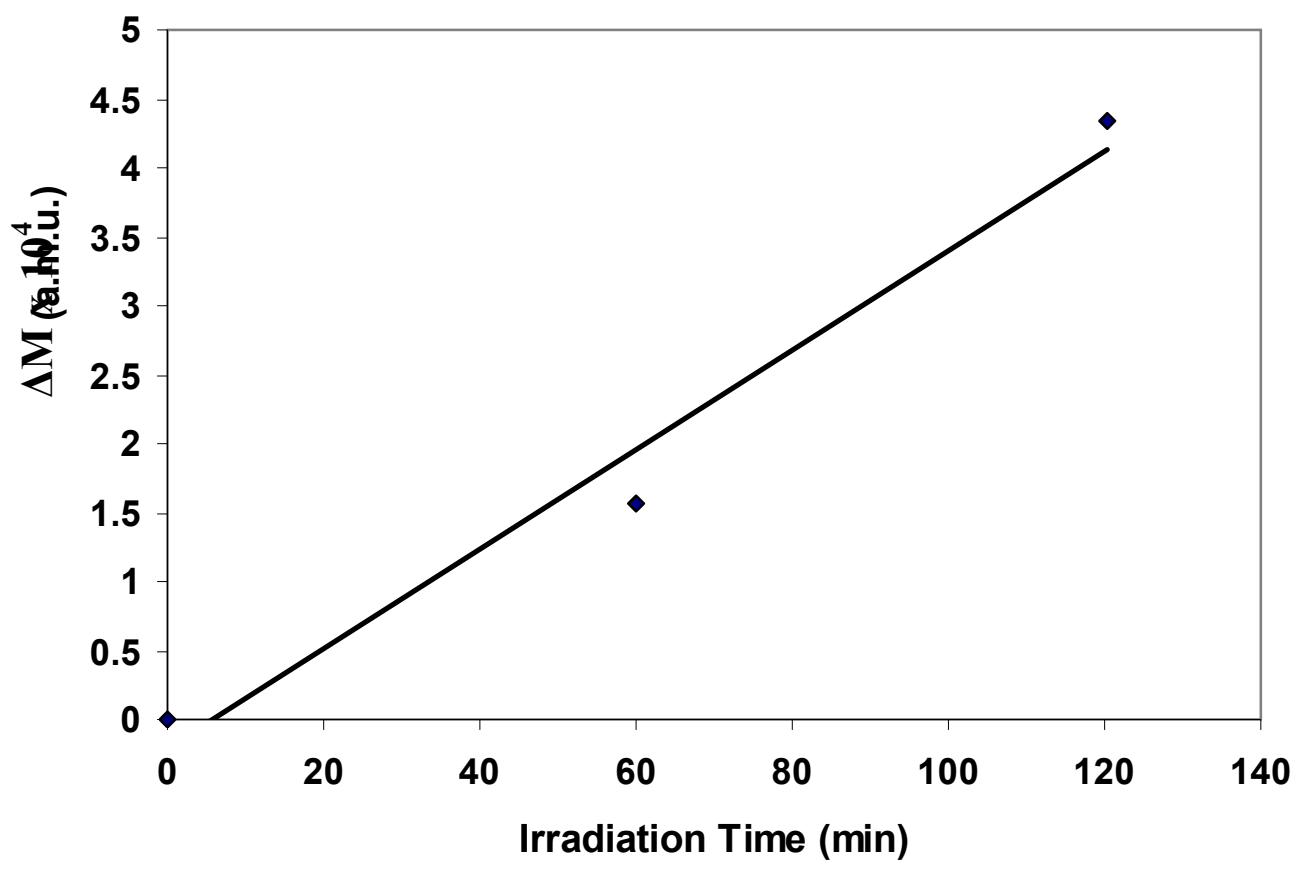

Fig (5) Variation of $\Delta \mathrm{M}$ of Ps with irradiation time

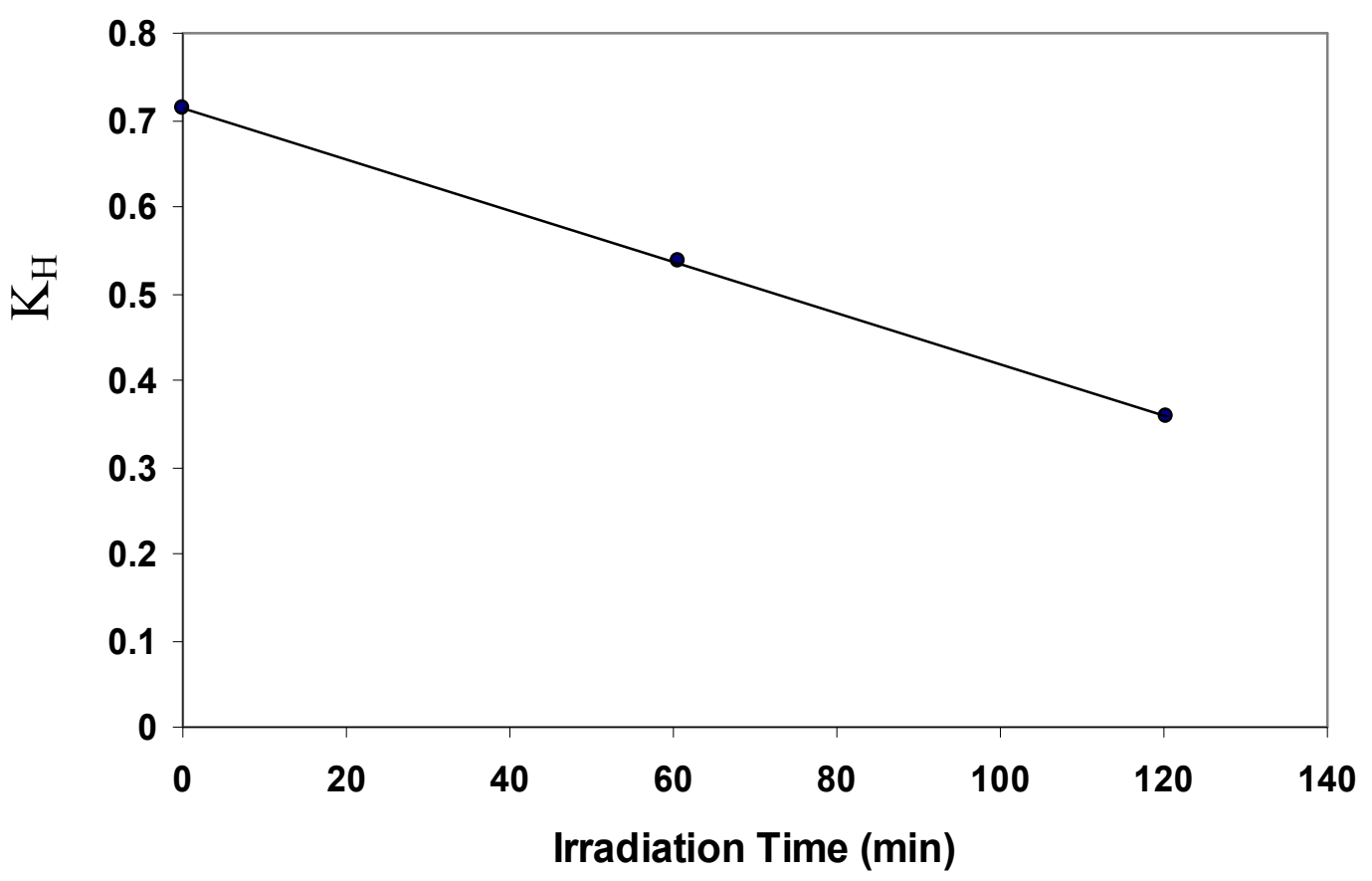

Fig (6) Variation of $K_{H}$ with irradiation time 
M. S. Buni \& W. A. Solyman \& S. A. Ali

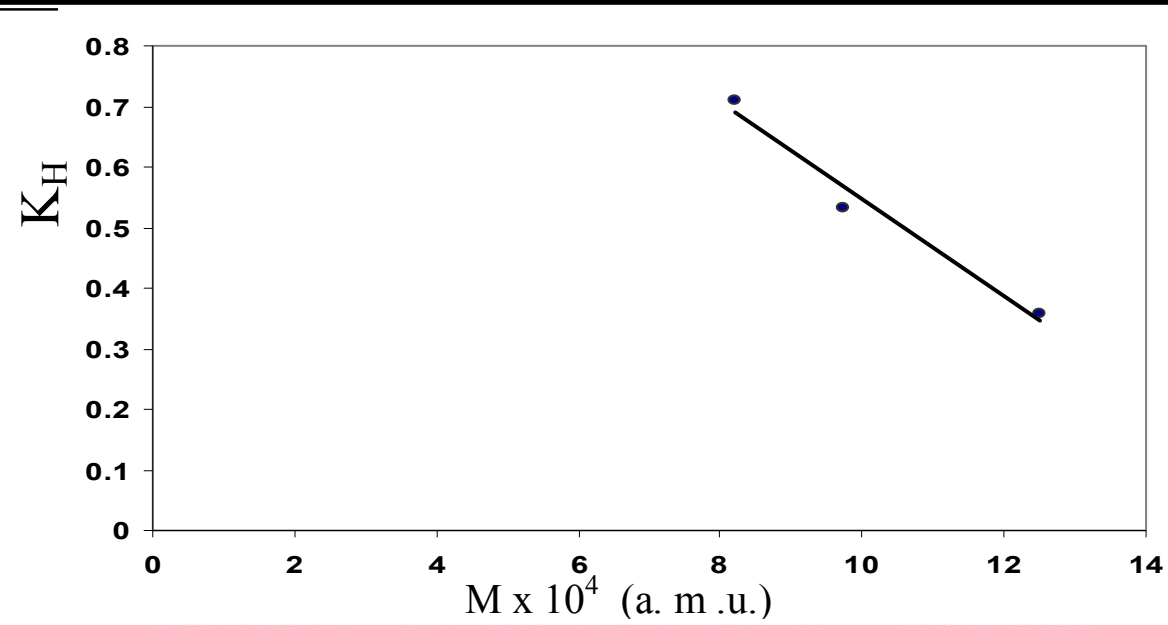

Fig (7) Variation of $K_{H}$ with molecular weight (M)

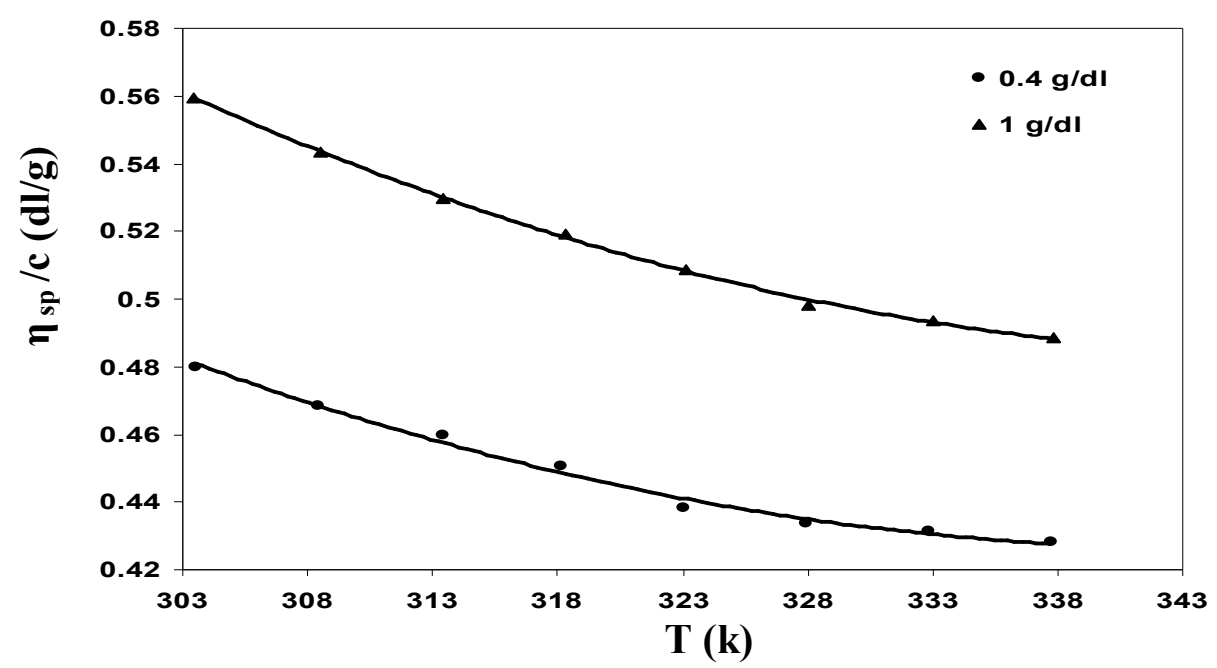

Fig (8) Variation of $\eta_{\mathrm{sp}} / \mathrm{C}$ with temp.

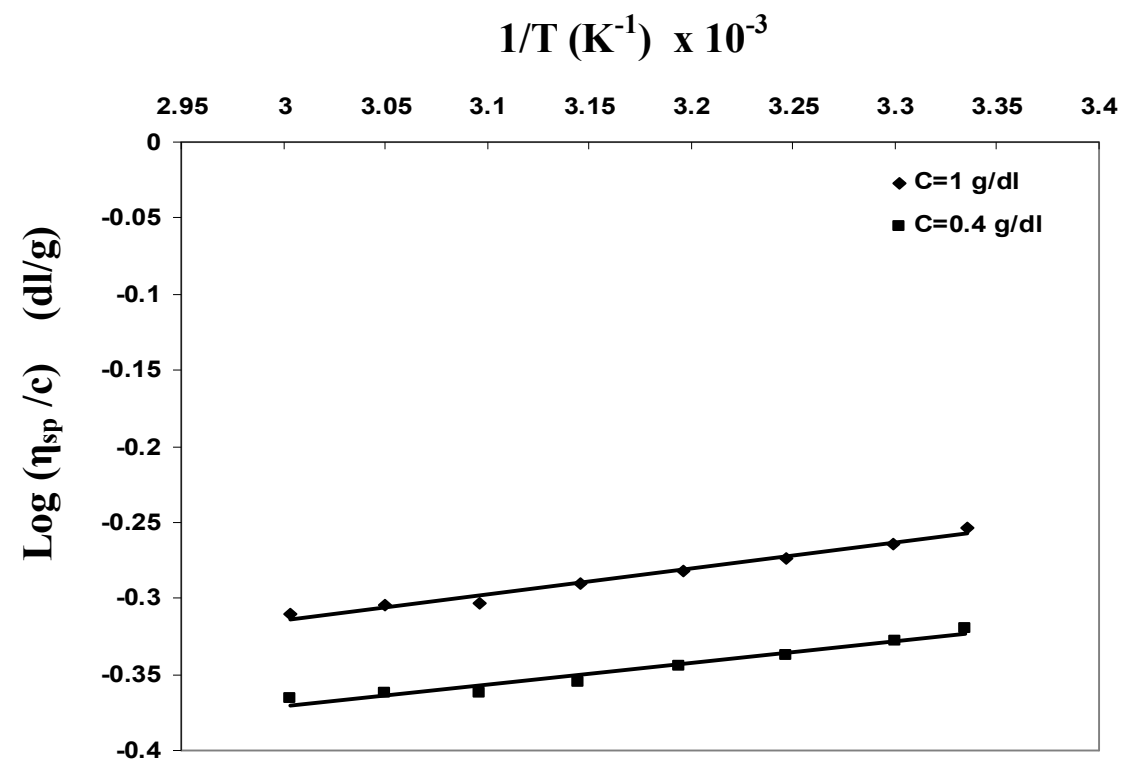

Fig (9) Dependence of $\log \eta_{\mathrm{sp}} / C$ on the reciprocal temp. 